\title{
Psychological Impact of COVID-19 Duties During Lockdown on Police Personnel and Their Perception About the Behavior of the People: an Exploratory Study from India
}

\author{
Sandeep Grover ${ }^{1} \cdot$ Swapnajeet Sahoo ${ }^{1} \cdot$ Devakshi Dua $^{1} \cdot$ Aseem Mehra ${ }^{1} \cdot$ Ritu Nehra $^{1}$
}

Accepted: 2 October 2020 / Published online: 5 November 2020

(C) Springer Science+Business Media, LLC, part of Springer Nature 2020

\begin{abstract}
To evaluate the psychosocial issues among the police personnel during the COVID-19 pandemic. In a web-based cross-sectional survey, 623 police personnel were evaluated on Patient Health Questionnaire-4 (PHQ-4) and Perceived stress scale (PSS), and a selfdesigned questionnaire. $10.6 \%$ of the police personnel had significant anxiety and $18 \%$ have significant depressive symptoms with overall psychological morbidity of $22.2 \%$. Higher age was significantly associated with higher depressive symptoms, total PHQ-4 score, and higher perceived stress. The present survey suggests that a substantial proportion of the police personnel on COVID-19 duty during the lockdown period have significant anxiety, depressive symptoms, and perceive significant stress. There is an urgent need to evaluate the mental health issues and provide psychological support to the police personnel who are considered as faceless warriors of the COVID-19.
\end{abstract}

Keywords COVID-19 $\cdot$ Police personnel $\cdot$ Anxiety $\cdot$ Depression $\cdot$ Stress

The outbreak of COVID-19 pandemic infection is a major health hazard that no one can disagree with. As per current statistics (dated 17 May 2020), more than 44 lakhs confirmed cases, and 3 lakhs deaths attributed to COVID-19 had been reported and the numbers are rising steeply across the globe (World Health Organization n.d.). India has also been affected significantly, and to control the spread of infection, the Government of India had taken several rigorous steps since mid-March 2020. One of the most effective strategies to control the spread of COVID-19 is "lockdown", which was declared with effect from 24 March 2020 across the

Supplementary Information The online version contains supplementary material available at https://oi. org/10.1007/s11469-020-00408-8.

Sandeep Grover

drsandeepg2002@yahoo.com

1 Department of Psychiatry, Post Graduate Institute of Medical Education and Research, Chandigarh, India 
country and has been extended phase-wise, and currently, India enters the lockdown 4.0 (The Hindu Net 2020) and there is every possibility that such strict measures to control crowds and free movements will be extended from many months across the country (with possible relaxation to some extent) soon.

Law enforcement services play a crucial role in contributing to the effort to control the pandemic worldwide. To have this "lockdown" strategy in place, the police personnel across the country have been deputed on duty to avoid crowding in public places, checking the movements of people on roads, patrolling the residential areas, ensuring the safety of healthcare workers, controlling cyber-threats, performing raids on fake medicines/sanitizers/ masks production, providing e-passes to the needy people traveling outside the curfew areas, etc., round the clock in addition to their normal duties related to enforcement of law and crime control. This had led to an increase in the duty hours of the police personnel apart from their normal scheduled duties of maintaining law and order. These extraordinary duties of the police personnel are almost equivalent to the duties of the health care workers (HCWs) who are engaged in the management of COVID-19 positive/suspected cases and are quite stressful. This is exemplified by recent reports of police personnel getting infected with COVID-19 while on duty and deaths of police personnel related to COVID-19 infection have been recently reported from across the country (Two more Mumbai cops die of Covid-19 2020). There are also reports of violence against the police on COVID-19 duties, with one of the reports suggesting severe assault and chopping off of a hand of police personnel who was trying to control movement restrictions in Punjab (India) (Policemen attacked by 'Nihangs' in Punjab, ASI's hand chopped off | Business Standard News n.d.).

While the mental health issues of the front line warriors, i.e., the health care workers (HCWs), have been widely acknowledged, and many countries have started providing psychological first aid to their healthcare workers(Zhang et al. 2020), the mental health issues of the police are largely neglected. Experts across the world have stressed upon the fact that policing during the pandemic is "emotionally taxing" on police officers on duty and this effect will be almost similar to the 9/11 trauma for law enforcement officers in the current as well as the near future (A. B. C. n.d.). Moreover, the Police Federation of England had alerted the health authorities that the police officers are operating in a "pressure cooker" like environment and are exposed to all sorts of trauma (physical and psychological) during this ongoing pandemic (Expert offers tips on caring for mental health during coronavirus pandemic n.d.). Another important pertinent issue among police personnel is that they are not very vocal about their stress and mental health issues (Newschannel 3 2020).

There is sufficient evidence to document the job-related stress among the police officers/ staff due to long work schedules/working hours, job-related traumatic events, non-availability of adequate leaves/duty off periods, getting exposed to human suffering and death very frequently, etc. (Collins and Gibbs 2003; Violanti et al. 2017). All these are potential stressors in the police staff which can lead to significant mental health or psychological problems in them. There have been instances of high rates of depression, substance abuse, and suicide in the police staff (Di Nota et al. 2020; Edwards and Kotera 2020). So far, only a few studies have focused on the mental/psychological consequences of perceived work stress in police officers and public safety workers during natural and human-made disasters and have reported high rates of post-traumatic stress disorder (PTSD) and depression in them (Benedek et al. 2007; Gershon et al. 2009). A cross-sectional survey conducted among police personnel $(n=912)$ after Hurricane Katrina in the USA (2015) revealed that a substantial proportion of officers reported PTSD (26\%) and depression (19\%). Various risk factors that were associated with the 
development of PTSD and depression in these studies included involving in the recovery of dead bodies, crowd control, assault and injury to a family member, staying isolated from the police department, and away from home during the difficult situations (West et al. 2008).

Although, since the outbreak of the COVID-19 pandemic, many researchers have evaluated the mental health issues among the HCWs (Chatterjee et al. 2020; Lai et al. 2020; Ni et al. 2020), there is no systemic study involving the police personnel. Keeping all these in mind, and considering the police work to be physically, emotionally, and mentally taxing, taking appropriate steps to mitigate psychological support to police staff is highly essential. During the current pandemic, there is added risk of getting infected as well as infecting own family members. This has led police personnel to avoid visiting their family members, and in many states, they have been staying in isolation similar to HCWs. This further can take a heavy mental toll on the police personnel, which is not being talked about by any health authority or national authority at large. In this background, this pilot project aimed to evaluate the psychosocial issues among the police personnel during the COVID-19 pandemic. Additionally, we also evaluated the police's perception of public behavior to the compliance with the measures advised for controlling the spread of COVID-19 infection.

\section{Methodology}

It was an online survey conducted using the Survey Monkey platform. For this, a survey link was generated, which was circulated by using the Whatsapp, after seeking permission from the appropriate authorities. The study was approved by the Institute's Ethics Committee. The survey invitation clearly stated that the participants would have the right not to participate in the survey and participation in the survey would imply providing informed consent. The survey link clearly stated that those not willing to participate can ignore the message.

To be included in the study, the participants were required to be part of the police personnel and currently on duty. Those without an access to a smart phone device were excluded from the study.

The survey questionnaire was made available in English and the local languages. It consisted of the following instruments:

\section{Demographics and Personal Characteristics}

A basic information sheet that included variables such as age, gender, marital status, educational qualifications, current job profile, and duty-related questions, etc.

A self-designed questionnaire was used to evaluate the psychosocial impact of prolonged and extraordinary lockdown duty hours on police personnel during COVID-19 in different aspects of their life. The items were selected for the self-designed questionnaire, based on the available media reports and interaction with few police personnel who were on duty.

\section{Patient Health Questionnaire-4 (PHQ-4) (Kroenke et al. 2009)}

The PHQ-4 is an ultra-brief screening instrument to detect both depression and anxiety and has 2 items each from PHQ-9 and Generalised Anxiety Questionnaire-7 (GAD-7). It had been validated in primary care clinics and the general population (Löwe et al. 2010) and has high internal reliability (Cronbach's $\alpha-0.81$ ) (Khubchandani et al. 2016; Materu et al. 2020). 


\section{Perceived Stress Scale-4 (PSS-4) (Vallejo et al. 2018)}

It is a 4-item questionnaire derived from PSS-10 (Cohen et al. 1983) and has been found to have adequate validity and good internal consistency (Cronbach's $\alpha-0.79$ to 0.82 ) in assessing stress perception levels in the general population and in special sub-groups of population in different countries (Karam et al. 2012; Lee 2012; Mitchell et al. 2008). A higher score indicates a high perception of stress.

The survey was circulated in English and local language (Punjabi) to the police personnel from 9 May 2020 to 18 May 2020, during which India had entered into an extended period of lockdown (from 4 May 2020 onwards to 31 May 2020). The link was circulated by the snowballing method, with police officers receiving the message were requested to forward the link to their colleagues through Whatsapp. The responders were given an option to provide their contact numbers if they wished to be contacted (i.e., optional) and 377 police personnel gave their contact numbers who were individually contacted by mental health professionals to explore for any kind of stress and psychological issues in them.

Descriptive statistics were applied and the data collected were analyzed using SPSS 20.0 version. Pearson's correlation coefficient and Spearman's correlation coefficient were used to finding the association between different variables.

\section{Results}

During the survey period, a total of 623 responses were collected during the survey period, i.e., from 9 May 2020 to 18 May 2020. The mean age of the participants (623 responses) was 36.98 (SD, 10.93) years. The majority of the participants (85.4\%) were males and were married and living with their spouse (67.7\%). About half of the participants had completed graduation or a higher level of studies $(51.2 \%)$. In terms of the current place of duty, one third of the participants were deployed at police stations/police lines (36.1\%). In terms of field duty, about one fifth $(18.3 \%)$ were mainly involved in managing the crowd at roads (18.3\%), patrolling $(13.5 \%)$, and at market places $(10.4 \%)$ and about $14.1 \%$ were deployed in miscellaneous places such as religious places, interstate borders, and interdistrict borders (please see Supplementary Table A).

\section{Prevalence of Perceived Stress, Anxiety, Depression Among the Police Personnel on Duty During COVID Pandemic}

The mean PSS-4 score for the study participants was 5.82 (SD - 2.64). The mean PHQ-4 score was 1.94 (SD - 2.63) with $10 \%$ of the participants reporting significant anxiety and depressive symptoms as per the PHQ-4 grading. When cut-off scores of each domain (i.e., anxiety and depression) were taken into account separately, $10.6 \%$ of the participants reported anxiety and $18 \%$ reported depressive symptoms. About $4 \%$ of participants reported only anxiety symptoms and about $11.6 \%$ reported only depressive symptoms. Both anxiety and depressive symptoms were taken together; only $6.4 \%$ reported both anxiety and depressive symptoms. Overall $22.2 \%$ of the police personnel screened positive for depression and/or anxiety (Table 1). 
Table 1 Prevalence of perceived stress, anxiety, and depression among the police personnel on duty during COVID pandemic

\begin{tabular}{|c|c|}
\hline Variables & $\begin{array}{l}\text { Whole sample }(n=623) \\
\text { Mean }(\mathrm{SD}) / \text { frequency }(\%)\end{array}$ \\
\hline \multicolumn{2}{|l|}{ PSS-4 item scores } \\
\hline PSS-1: Unable to control the important things in your life & $0.92(1.14)$ \\
\hline PSS-2: Confident about your ability to handle your personal problems & $1.73(1.33)$ \\
\hline PSS-3: That things were going your way & $2.30(1.31)$ \\
\hline PSS-4: Difficulties were piling up so high that you could not overcome them & $0.86(1.08)$ \\
\hline Mean PSS-4 score & $\begin{array}{l}5.82(2.64) ; \text { range } 0-14 \\
\text { median } 6.00\end{array}$ \\
\hline \multicolumn{2}{|l|}{ PHQ-4 Scale } \\
\hline PHQ-4 Anxiety domain (2 items) & $0.78(1.33)$; range $0-6$ \\
\hline Anxiety: Present (cut off score $\geq 3$ ) & $66(10.6 \%)$ \\
\hline PHQ-4 Depression domain (2 items) & 1.15 (1.53); range $0-6$ \\
\hline Depression: Present (Cut off $\geq 3$ ) & $112(18.0 \%)$ \\
\hline Mean total PHQ-4 score & $\begin{array}{l}1.94(2.63) ; \text { range } 0-12 \\
\text { Median } 1.0\end{array}$ \\
\hline \multicolumn{2}{|l|}{ The severity of depression and anxiety as per PHQ-4 } \\
\hline Normal $(0-2)$ & $417(66.9 \%)$ \\
\hline Mild (3-5) & $144(23.1 \%)$ \\
\hline Moderate (6-8) & $37(5.9 \%)$ \\
\hline Severe $(9-12)$ & $25(4.0 \%)$ \\
\hline \multicolumn{2}{|l|}{ Overall prevalence } \\
\hline$\%$ of responders reporting PHQ-4 anxiety score $\geq 3$ & $66(10.6 \%)$ \\
\hline$\%$ of responders reporting PHQ- 4 depression score $\geq 3$ & $112(18.0 \%)$ \\
\hline$\%$ of responders reporting only anxiety but no depression & $26(4.2 \%)$ \\
\hline$\%$ of responders reporting only depression but no anxiety & $72(11.6 \%)$ \\
\hline$\%$ of responders reporting both anxiety and depression as per PHQ-4 & $40(6.4 \%)$ \\
\hline
\end{tabular}

\section{Effect of COVID-19 Duties on Emotions, Feelings, and Various Aspects of the Life of the Police Personnel}

The effect of COVID-19 duties after a lockdown on emotions, feelings, and various aspects of life was evaluated on a self-designed Likert scale with the options of "not at all," "sometimes," "most of the time," and "always" (Table 2).

More than half of the participants reported that they were feeling tense about the increase in the workload and more than half of the participants were not able to sleep properly at least for "sometimes", since the onset of the lockdown. About two fifth of the participants reported that at least for "sometimes", they were feeling scared of not get support from the administration and not getting adequate Personal Protective Equipment. In terms of negative emotional response, about one third to one fourth of responders reported experiencing feelings of anger, demoralization, irritability, loneliness, disconnectedness, and being used "sometimes/most of the time/always." About one fifth of the participants "sometimes/most of the time/always" felt like running away from the work and were scared of death. Among all these adverse situations and feelings, about one third reported that they were "always" feeling optimistic about the situation, and about two thirds reported feeling proud of themselves (Table 2). 
Table 2 Effect of COVID-19 duties on emotions, feelings, and various aspects of the life of the police personnel $(n=623)$

\begin{tabular}{|c|c|c|c|c|}
\hline & $\begin{array}{l}\text { Not at all } \\
\text { Frequency }(\%)\end{array}$ & $\begin{array}{l}\text { Sometimes } \\
\text { Frequency }(\%)\end{array}$ & $\begin{array}{l}\text { Most of the time } \\
\text { Frequency }(\%)\end{array}$ & $\begin{array}{l}\text { Always } \\
\text { Frequency }(\%)\end{array}$ \\
\hline Feeling angry & $434(69.7)$ & $151(24.2)$ & $29(4.7)$ & $9(1.4)$ \\
\hline Feeling demoralized & $449(72.1)$ & $143(23.0)$ & $28(4.5)$ & $3(0.5)$ \\
\hline Feeling irritable & $405(65.0)$ & $178(28.6)$ & $33(5.3)$ & $7(1.1)$ \\
\hline Feeling lonely & $426(68.4)$ & $146(23.4)$ & $41(6.6)$ & $10(1.6)$ \\
\hline Feeling socially disconnected & $412(66.1)$ & $166(26.6)$ & $33(5.3)$ & $12(1.9)$ \\
\hline Feeling useful & $222(35.6)$ & $177(28.4)$ & $103(16.5)$ & $121(19.4)$ \\
\hline Feeling being used & $456(73.2)$ & $114(18.3)$ & $23(3.7)$ & $30(4.8)$ \\
\hline Feeling like running away from work & $486(78.0)$ & $118(18.9)$ & $16(2.6)$ & $3(0.5)$ \\
\hline Feeling optimistic & $153(24.6)$ & $140(22.5)$ & $106(17.0)$ & $224(36.0)$ \\
\hline Scared of death & $489(78.5)$ & $107(17.2)$ & $14(2.2)$ & $13(2.1)$ \\
\hline Feeling proud of yourself & $38(6.1)$ & $72(11.6)$ & $117(18.8)$ & $396(63.6 \%)$ \\
\hline $\begin{array}{l}\text { Scared that you will not get support from } \\
\text { the administration }\end{array}$ & $367(58.9)$ & $180(28.9)$ & $43(6.9)$ & $33(5.3)$ \\
\hline $\begin{array}{l}\text { Scared that you will not get adequate } \\
\text { Personal Protective Equipment }\end{array}$ & $361(57.9)$ & $185(29.7)$ & $47(7.5)$ & $30(4.8)$ \\
\hline Not able to sleep properly. & $279(44.8)$ & $263(42.2)$ & $46(7.4)$ & $35(5.6)$ \\
\hline Tense about the increase in the workload & $297(47.7)$ & $257(41.3)$ & $53(8.5)$ & $16(2.6)$ \\
\hline
\end{tabular}

\section{Perceived Fear of Infecting Self and Family and the Reaction of Family Members for Being on COVID-19 Duties}

As evident from Table 3, while $30 \%$ of the responders were very scared of infecting their family members with COVID-19, only $6 \%$ were "very scared" of themselves contracting infection. Further, the majority of the responders reported that their family was "always" happy for them being on duty (63.9\%) and only $29.5 \%$ reported that their family was "always" worried about them being on COVID duties. Moreover, only $16.7 \%$ of responders reported that their family was "always" worried about them getting infection to home (16.7\%).

Table 3 Perceived fear of infecting self and family and the reaction of family members for being on COVID-19 duties

\begin{tabular}{|c|c|c|c|c|}
\hline Perceived fear of infecting & $\begin{array}{l}\text { Very scared } \\
\text { Frequency }(\%)\end{array}$ & $\begin{array}{l}\text { Somewhat } \\
\text { scared } \\
\text { Frequency }(\%)\end{array}$ & $\begin{array}{l}\text { A bit scared } \\
\text { Frequency }(\%)\end{array}$ & $\begin{array}{l}\text { Not at all scared } \\
\text { Frequency }(\%)\end{array}$ \\
\hline $\begin{array}{l}\text { How much you are scared of infecting } \\
\text { your family members? }\end{array}$ & $182(29.2)$ & $194(31.1)$ & $82(13.2)$ & $165(26.5)$ \\
\hline $\begin{array}{l}\text { How much you are scared of infecting } \\
\text { yourself? }\end{array}$ & $38(6.1)$ & $159(25.5)$ & $150(24.1)$ & $276(44.3)$ \\
\hline \multirow[t]{2}{*}{ The reaction of family members } & Not at all & Sometimes & Most of the time & Always \\
\hline & Frequency $(\%)$ & Frequency $(\%)$ & Frequency $(\%)$ & Frequency $(\%)$ \\
\hline $\begin{array}{l}\text { My family is happy for me being } \\
\text { on duty }\end{array}$ & $28(4.5)$ & $50(8.0)$ & $147(23.6)$ & $298(63.9)$ \\
\hline $\begin{array}{l}\text { My family is worried about me } \\
\text { getting ill }\end{array}$ & $125(20.1)$ & $195(31.3)$ & $119(19.1)$ & $184(29.5)$ \\
\hline $\begin{array}{l}\text { My family is worried about me } \\
\text { getting the infection home }\end{array}$ & $190(30.5)$ & $229(36.8)$ & $100(16.1)$ & 104(16.7) \\
\hline
\end{tabular}




\section{Self-Reported Change in Relationship and Interaction with Family and Friends, Because of Being on Duty During the COVID-19}

On various social and relational issues, more than half of the responders reported reduction (marked or slight) in their ability to meet and interact with their children, parents, spouse/ partner, and friends due to COVID-19 duties (Table 4).

\section{The Opinion of the On-Duty Police Personnel on the Behavior of the Public During the Lockdown}

Nearly half of the responders reported public to have been or compliant with lockdown enforcement strategies and the majority of public complied with staying at home, maintained social distancing norms, and used masks and sanitizers as advised (Table 5). However, about one third of the responders reported that most people were non-compliant to lockdown rules, and law and order, staying at home, and maintaining social distancing at desired places (like markets, vegetable markets, grocery stores). Moreover, the participants reported about one fifth of the public were non-compliant with the use of masks (19.6\%) and one fourth of the public was not compliant with the use of sanitizers (27.4\%) (Table 5).

\section{Association Between Time Since Lockdown, Age, and Other Demographic Factors with Perceived Stress, Anxiety, and Depression}

Higher age was significantly associated with higher depressive symptoms, total PHQ-4 score, and also with higher perceived stress. There was a significant positive association between depressive symptoms, anxiety symptoms, and perceived stress (please see Supplementary Table B).

\section{Gender Differences}

When the male and female participants were compared, in contrast to males, significantly higher proportion of female police personnel more often reported feeling demoralized (chisquare value $-23.177 ; p$ value $<0.001$ ), irritable (chi-square value $-25.113 ; p$ value $<0.001$ ), lonely (chi-square value $-12.9, p$ value $=0.005$ ), socially disconnected (chi-square value -

Table 4 Self-reported change in relationship and interaction with your family and friends, because of being on duty during the COVID-19

\begin{tabular}{llllll}
\hline & $\begin{array}{l}\text { Markedly } \\
\text { decreased } \\
\text { Frequency }(\%)\end{array}$ & $\begin{array}{l}\text { Slightly } \\
\text { decreased } \\
\text { Frequency }(\%)\end{array}$ & $\begin{array}{l}\text { No change } \\
\text { Frequency } \\
(\%)\end{array}$ & $\begin{array}{l}\text { Slightly } \\
\text { improved } \\
\text { Frequency (\%) }\end{array}$ & $\begin{array}{l}\text { Markedly } \\
\text { Frequency }(\%)\end{array}$ \\
\hline Meeting your children & $215(34.5)$ & $201(32.3)$ & $144(23.1)$ & $23(3.7)$ & $40(6.4)$ \\
Meeting your parents & $199(31.9)$ & $216(34.7)$ & $142(22.8)$ & $27(4.3)$ & $39(6.3)$ \\
Meeting your & $190(30.5)$ & $189(30.3)$ & $194(31.1)$ & $20(3.2)$ & $30(4.8)$ \\
$\quad$ spouse/partner & $356(57.1)$ & $145(23.3)$ & $71(11.4)$ & $22(3.5)$ & $29(4.7)$ \\
Meeting friends & $182(29.2)$ & $201(32.2)$ & $177(28.4)$ & $23(3.7)$ & $40(6.4)$ \\
Interaction with children & $176(28.3)$ & $30(4.8)$ & $43(6.9)$ \\
Interaction with parents & $161(25.8)$ & $213(34.2)$ & $213(34.2)$ & $22(3.5)$ & $40(6.4)$ \\
Interaction with & $155(24.9)$ & $193(31.0)$ & $213)$ & $17(2.7)$ & $41(6.6)$ \\
$\quad$ spouse/partner & $224(36.0)$ & $209(33.5)$ & $132(21.2)$ & $17)$ \\
Interaction with friends & & &
\end{tabular}


Table 5 Opinion of the on-duty police personnel on the behavior of the public because of the lockdown

\begin{tabular}{lclll}
\hline Variables & $\begin{array}{l}\text { All people have } \\
\text { been compliant } \\
\text { Frequency }(\%)\end{array}$ & $\begin{array}{l}\text { Most people } \\
\text { are compliant } \\
\text { Frequency }(\%)\end{array}$ & $\begin{array}{l}\text { Most people are } \\
\text { non-compliant } \\
\text { Frequency (\%) }\end{array}$ & $\begin{array}{l}\text { All people have } \\
\text { been non-compliant } \\
\text { Frequency }(\%)\end{array}$ \\
\hline Compliance with lockdown & $90(14.4 \%)$ & $258(41.4 \%)$ & $226(36.3 \%)$ & $49(7.9 \%)$ \\
Compliance with law and order & $105(16.9 \%)$ & $261(41.9 \%)$ & $212(34.0 \%)$ & $45(7.2 \%)$ \\
Compliance with staying at home & $77(12.4 \%)$ & $281(45.1 \%)$ & $220(35.3 \%)$ & $45(7.2 \%)$ \\
Compliance with maintaining & $92(14.8 \%)$ & $265(42.5 \%)$ & $215(34.5 \%)$ & $51(8.2 \%)$ \\
$\quad$ social distancing & $155(24.9 \%)$ & $308(49.4 \%)$ & $122(19.6 \%)$ & $38(6.1 \%)$ \\
Compliance with using mask & $124(19.9 \%)$ & $280(44.9 \%)$ & $171(27.4 \%)$ & $48(7.7 \%)$ \\
Compliance with using sanitizer & & &
\end{tabular}

$17.54, p$ value $=0.001$, running away from work (chi-square value $-16.83, p$ value $=0.001$ ), very scared of infecting family members (chi-square value $-10.95 ; p$ value -0.012 ), and their family being worried about them getting ill (chi-square value $-17.207 ; p$ value -0.001 ).

Compared to males, higher proportion of female police personnel screened positive for anxiety (18.7\% vs $9.2 \%$ in males; chi-square value $-7.359 ; p$ value -0.007$)$ and depression on PHQ-4 (26.4\% vs $16.5 \%$ in males; chi-square value $-5.095 ; p$ value -0.024$)$. Female police personnel also had higher anxiety ( $t$ test value $-4.230 ; p$ value $<0.001)$, and depression score $(t$ test value $-3.67 ; p$ value $<0.001)$ and higher total PHQ-4 score $(t$ test value $-4.291 ; p$ value $<0.001)$. No significant gender differences were noted on perceived stress scores.

\section{Discussion}

The police personnel are the main driving force and have been helping the nation in achieving success in maintaining strict lockdown measures across the country. While the mental health and psychological problems among the HCWs are largely acknowledged and being reported from different parts of the world during the ongoing COVID-19 pandemic, the mental health issues in security personnel, i.e., the police personnel who are also actively engaged all over the world in maintaining the lockdown are largely neglected and underreported. Accordingly, this study was planned as a pilot project to evaluate the psychosocial issues of the police personnel engaged in COVID-19 duty during the lockdown period.

A total of 623 police personnel participated in this online survey, and this sample size can be considered reasonable enough to draw definite inferences. The study revealed that $10.6 \%$ of the participants had significant anxiety and $18 \%$ had significant depressive symptoms as per the PHQ-4 scale. Overall, 22.2\% of the police personnel screened positive for depression and/ or anxiety which is a substantial number needing urgent attention. With no national data or any previous nationwide study evaluating the mental health problems/needs of the police personnel in India, we are unable to compare the prevalence findings with the existing data on police personnel. Few previous Indian studies focusing on the occupational stress factors in police personnel (Mumbai, Maharashtra, and Ghaziabad, Uttar Pradesh) doing normal routine duties had reported that about $18 \%$ of surveyed staff had a high degree of stress and about $73-88 \%$ were moderately stressed (Almale et al. 2014; Kamble and Phalke 2011). However, these studies were not adequately powered to be compared with the present study.

What does this data suggest? When we compare the findings of the depression and anxiety with the data of National Mental Health Survey, which suggests current morbidity of $2.8 \%$ and 
3.5\% for affective and anxiety disorders (Murthy 2017), it can be said that possibly the police personnel on COVID-19 have significantly higher psychiatric morbidity, which requires further evaluation. The findings of the present study should not be interpreted as psychiatric morbidity, as this has been evaluated by using brief screening instruments. However, it can also be said that these instruments are sensitive enough to pick-up psychiatric morbidity as determined by detailed psychiatric evaluation. Hence, these findings cannot be completely ignored too. These findings suggest that there is an urgent need for screening, proper diagnosis, and management of psychiatric issues in police personnel. These findings also possibly suggest the need for psychological help for police personnel, who are facing significant stress due to the pandemic. In general police personnel are in the news for wrong reasons, such as violating human rights and abusing people (India: Human Rights Violations and Police Brutality in Uttar Pradesh Statement by SOS-Torture Asia Litigators Group / January 1, 2020 / Statements / Press Releases / OMCT n.d.; The Misuse of 'Lathi Charge' by the Indian Police n.d.; Mangoli and Tarase 2010; Murthy 2017). People, in general, do not seek the perspectives of police and the kind of stress they face in managing/maintaining the law and order of the State. Hence, there is a need to make the general public aware of the stress faced by the police in managing the law and order, so that they comply with the proposed rules and regulations. This may help in the reduction of stress on the police personnel.

Earlier studies on police personnel had mostly focused on the organizational job-related stress and burnout(Arial et al. 2010; Collins and Gibbs 2003; Nelson and Smith 2016) and have reported significant job-related stress. The present study also revealed that the perceived stress in the police personnel on COVID-19 duty was quite high (PSS-4 mean score -5.82 ; SD - 2.64) and the perceived stress was significantly associated with depressive and anxiety symptoms in the study sample. The nature of COVID-19 stress is slightly different from usual reported occupational stress as there is a component of perceived fear of getting infected as well as infecting own family members. In contrast to the HCWs, there is no provision of quarantine among police personnel after the duty of 1-2 weeks and they are expected to go back home. This can explain the stress and fear related to infecting the family members and the impact of the same on interaction and meeting the family members. About the effect of COVID-19 duties on emotions, feelings and various aspects of the life of the police personnel, it was found that more than half of the participants reported that they were feeling tense about the increase in the workload and were not able to sleep properly at least for "sometimes," since the onset of the lockdown. About two fifth of the participants reported that at least for "sometimes," they were feeling scared of not getting support from the administration and not getting adequate Personal Protective Equipment (PPEs). Further, negative emotional responses in the form of experiencing feelings of anger, demoralization, irritability, loneliness, disconnectedness, and being used were reported by about one third to one fourth of the study responders. All these findings suggest that the COVID-19 duties which are beyond the usual duty of just maintaining law and order are taking a major psychological toll on the police personnel.

The present study also reveals that compared to males, female police personnel is facing a higher level of stress, depression, anxiety, and negative emotional states. These findings can be understood in the background of the fact that despite being on job, females are expected to continue with their household responsibilities (From Reel to Real Life, Challenges Faced by Women in Police Are Manifold n.d.; Joshi 2015). This can explain the higher negative impact on females. 
As the COVID-19 pandemic is going to persist for some time and this high level of stress is going to possibly persist and increase, there is a need to develop a policy for the police personnel, so that their duty hours can be regulated, they can be provided with adequate protective gears and there should be provision for their isolation in safe places, like that for HCWs. Governments should also take necessary and immediate steps to mitigate the psychological impact of the COVID-19 pandemic on the police personnel by holding stress management programs and evaluating at-risk police personnel and providing timely psychiatric help by mental health professionals.

This study has certain limitations. It was an online cross-sectional study and was limited to police personnel who had smartphones with Whatsapp services. The police personnel on COVID-19 duties may be overworked and many may not have responded to the link shared. Moreover, the study findings are based upon screening instruments and no definite gold standard face to face interview was conducted. The self-designed questionnaire has not been validated. However, the strengths of the study include it being the first study which had tried to systematically evaluate the psychosocial issues in the police personnel on COVID-19 duty across the World. The survey was circulated in English, and the local language which could have enhanced the study findings. Further, all those who wished to be contacted by the mental health professionals were contacted telephonically and were evaluated based on their responses. Future studies should evaluate the police personnel more thoroughly to understand the psychological impact of the pandemic on police and security personnel.

To conclude, the current study revealed that about $10.6 \%$ of the police personnel have significant anxiety and $18 \%$ have significant depressive symptoms with overall psychological morbidity of $22.2 \%$. The present study also suggests that the current COVID-19 pandemic has led to significant stress and negative emotional response among the police personnel. The impact appears to be higher on female police personnel than on the male police personnel. These findings suggest that there is a need to expand mental health services to address the psychological issues among police personnel.

Acknowledgments We thank all the police personnel, who spared their time to complete this survey.

\section{Compliance with Ethical Standards}

Conflict of Interest The authors declare that they have no conflicts of interest.

Ethical Approval The research was approved by the Institute's Ethics Committee at Post graduate Institute of Medical Education and Research, Chandigarh, India. All procedures performed in this study were in accordance with the ethical standards of the institutional and/or national research committee and with the 1964 Helsinki declaration and its later amendments or comparable ethical standards.

Informed Consent Informed written consent was obtained from all individual participants included in the study. The survey invitation clearly stated that the participants would have the right not to participate in the survey and participation in the survey would imply providing informed consent. The survey link stated clearly that those not willing to participate ignore the message.

Registry and the Registration Number of the Study Post graduate Institute of Medical Education and Research (PGIMER), Chandigarh (No. INT/IEC/2020/SPL-552). 


\section{References}

A. B. C., N. (n.d.). Law enforcement groups urge mental health awareness amid coronavirus [WWW Document]. ABC News. https://abcnews.go.com/Politics/law-enforcement-groups-urge-mental-health-awarenessamid/story?id=70667340. Accessed 5.17.20.

Almale, B. D., Vankudre, A. J., Bansode-Gokhe, S. S., \& Pawar, V. K. (2014). An epidemiologic study of occupational stress factors in Mumbai police personnel. Indian Journal of Occupational and Environmental Medicine, 18, 109-112. https://doi.org/10.4103/0019-5278.146906.

Arial, M., Gonik, V., Wild, P., \& Danuser, B. (2010). Association of work related chronic stressors and psychiatric symptoms in a Swiss sample of police officers; a cross sectional questionnaire study. International Archives of Occupational and Environmental Health, 83, 323-331. https://doi.org/10.1007 /s00420-009-0500-Z.

Benedek, D. M., Fullerton, C., \& Ursano, R. J. (2007). First responders: Mental health consequences of natural and human-made disasters for public health and public safety workers. Annual Review of Public Health, 28, 55-68. https://doi.org/10.1146/annurev.publhealth.28.021406.144037.

Chatterjee, S. S., Bhattacharyya, R., Bhattacharyya, S., Gupta, S., Das, S., \& Banerjee, B. B. (2020). Attitude, practice, behavior, and mental health impact of COVID-19 on doctors. Indian Journal of Psychiatry, 62, 257-265. https://doi.org/10.4103/psychiatry.IndianJPsychiatry 33320.

Cohen, S., Kamarck, T., \& Mermelstein, R. (1983). A global measure of perceived stress. Journal of Health and Social Behavior, 24, 385-396.

Collins, P. A., \& Gibbs, A. C. C. (2003). Stress in police officers: A study of the origins, prevalence and severity of stress-related symptoms within a county police force. Occupational Medicine (Oxford England), 53, 256264. https://doi.org/10.1093/occmed/kqg061.

Di Nota, P. M., Anderson, G. S., Ricciardelli, R., Carleton, R. N., \& Groll, D. (2020). Mental disorders, suicidal ideation, plans and attempts among Canadian police. Occupational Medicine, 70, 183-190. https://oi. org/10.1093/occmed/kqaa026.

Edwards, A.-M., \& Kotera, Y. (2020). Mental health in the UK police force: A qualitative investigation into the stigma with mental illness. International Journal of Mental Health and Addiction. https://doi.org/10.1007 /s11469-019-00214-x.

Expert offers tips on caring for mental health during coronavirus pandemic [WWW Document]. (n.d.). https:/www.polfed.org/news-media/latest-news/2020/expert-offers-tips-on-caring-for-mental-health-duringpandemic/. Accessed 5.17.20.

From Reel to Real Life, Challenges Faced by Women in Police Are Manifold [WWW Document]. (n.d.). The wire. https://thewire.in/women/woman-police-officers-india. Accessed 5.18.20.

Gershon, R. R. M., Barocas, B., Canton, A. N., Li, X., \& Vlahov, D. (2009). Mental, physical, and behavioral outcomes associated with perceived work stress in police officers. Criminal Justice and Behavior, 36, 275289. https://doi.org/10.1177/0093854808330015.

India: Human Rights Violations and Police Brutality in Uttar Pradesh Statement by SOS-Torture Asia Litigators Group / January 1, 2020 / Statements / Press Releases / OMCT [WWW Document]. (n.d.). https://www. omct.org/press-releases/statements/india/2020/01/d25670/. Accessed 5.18.20.

Joshi, S. (2015). The state of women in police in India and the discrimination faced by them. The International Journal of Indian Psychology, 2, 1-7. https://doi.org/10.25215/0204.101.

Kamble, S. V., \& Phalke, D. B. (2011). Study of occupational stress as a risk factor for various morbidities among policemen. Journal of the Indian Medical Association, 109, 238-240.

Karam, F., Bérard, A., Sheehy, O., Huneau, M.-C., Briggs, G., Chambers, C., Einarson, A., Johnson, D., Kao, K., Koren, G., Martin, B., Polifka, J. E., Riordan, S. H., Roth, M., Lavigne, S. V., \& Wolfe, L. (2012). Reliability and validity of the 4-item perceived stress scale among pregnant women: Results from the OTIS antidepressants study. Research in Nursing \& Health, 35, 363-375. https://doi.org/10.1002/nur.21482.

Khubchandani, J., Brey, R., Kotecki, J., Kleinfelder, J., \& Anderson, J. (2016). The psychometric properties of PHQ-4 depression and anxiety screening scale among college students. Archives of Psychiatric Nursing, 30, 457-462. https://doi.org/10.1016/j.apnu.2016.01.014.

Kroenke, K., Spitzer, R. L., Williams, J. B. W., \& Löwe, B. (2009). An ultra-brief screening scale for anxiety and depression: The PHQ-4. Psychosomatics, 50, 613-621. https://doi.org/10.1176/appi.psy.50.6.613.

Lai, J., Simeng, M., Wang, Y., Cai, Z., Hu, J., Ning, W., Jiang, W., Hui, D., Tingting, C., Li, R., Tan, H., Kang, L., Yao, L., Huang, M., Wang, H., Wang, G., Liu, Z., \& Hu, S. (2020). Factors associated with mental health outcomes among health care workers exposed to coronavirus disease 2019. JAMA Network Open, 3, 3. https://doi.org/10.1001/jamanetworkopen.2020.3976.

Lee, E.-H. (2012). Review of the psychometric evidence of the perceived stress scale. Asian Nursing Research, 6 , 121-127. https://doi.org/10.1016/j.anr.2012.08.004. 
Löwe, B., Wahl, I., Rose, M., Spitzer, C., Glaesmer, H., Wingenfeld, K., Schneider, A., \& Brähler, E. (2010). A 4-item measure of depression and anxiety: Validation and standardization of the Patient Health Questionnaire-4 (PHQ-4) in the general population. Journal of Affective Disorders, 122, 86-95. https://doi.org/10.1016/j.jad.2009.06.019.

Mangoli, R.N., \& Tarase, G.M. (2010). A study of human rights violation by police in India. International Journal of Criminology \& Sociological Theory, 3, 401-418.

Materu, J., Kuringe, E., Nyato, D., Galishi, A., Mwanamsangu, A., Katebalila, M., Shao, A., Changalucha, J., Nnko, S., \& Wambura, M. (2020). The psychometric properties of PHQ-4 anxiety and depression screening scale among out of school adolescent girls and young women in Tanzania: A cross-sectional study. BMC Psychiatry, 20, 321. https://doi.org/10.1186/s12888-020-02735-5.

Mitchell, A. M., Crane, P. A., \& Kim, Y. (2008). Perceived stress in survivors of suicide: Psychometric properties of the Perceived Stress Scale. Research in Nursing \& Health, 31, 576-585. https://doi. org/10.1002/nur.20284.

Murthy, R. S. (2017). National Mental Health Survey of India 2015-2016. Indian Journal of Psychiatry, 59, 2126. https://doi.org/10.4103/psychiatry.IndianJPsychiatry_102_17.

Nelson, K. V., \& Smith, A. P. (2016). Occupational stress, coping and mental health in Jamaican police officers. Occupational Medicine (Oxford England)., 66, 488-491. https://doi.org/10.1093/occmed/kqw055.

Newschannel 3, T.H.| (2020). Battle Creek Police Department works to reduce mental strain during pandemic [WWW Document]. WWMT. https://wwmt.com/news/local/local-police-department-works-to-reducemental-strain-during-pandemic. Accessed 5.17.20.

Ni, M. Y., Yang, L., Leung, C. M. C., Li, N., Yao, X. I., Wang, Y., Leung, G. M., Cowling, B. J., \& Liao, Q. (2020). Mental health, risk factors, and social media use during the COVID-19 epidemic and cordon sanitaire among the community and health professionals in Wuhan, China: Cross-sectional survey. JMIR Mental Health, 7, e19009. https://doi.org/10.2196/19009.

Policemen attacked by "Nihangs" in Punjab, ASI's hand chopped off $\mid$ Business Standard News [WWW Document]. (n.d.). https://www.business-standard.com/article/current-affairs/policemen-attacked-bynihangs-in-punjab-asi-s-hand-chopped-off-120041200265_1.html. Accessed 5.17.20.

The Hindu Net, D. (2020). India lockdown 4.0 guidelines | What's allowed and what's not? The Hindu.

The Misuse of "Lathi Charge" by the Indian Police [WWW Document]. (n.d.). The wire. https://thewire. in/law/the-misuse-of-lathi-charge-by-the-indian-police. Accessed 5.18.20.

Two more Mumbai cops die of Covid-19 [WWW Document]n.d. (2020). Hindustan Times. https://www. hindustantimes.com/india-news/two-more-mumbai-cops-die-of-covid-19/story-waN1sFhCVgcqPoa8IN76 KO.html. Accessed 5.17.20.

Vallejo, M. A., Vallejo-Slocker, L., Fernández-Abascal, E. G., \& Mañanes, G. (2018). Determining factors for stress perception assessed with the Perceived Stress Scale (PSS-4) in Spanish and other European samples. Frontiers in Psychology, 9, 37. https://doi.org/10.3389/fpsyg.2018.00037.

Violanti, J. M., Charles, L. E., McCanlies, E., Hartley, T. A., Baughman, P., Andrew, M. E., Fekedulegn, D., Ma, C. C., Mnatsakanova, A., \& Burchfiel, C. M. (2017). Police stressors and health: A state-of-the-art review. Policing (Bradford, England)., 40, 642-656. https://doi.org/10.1108/PIJPSM-06-2016-0097.

West, C., Bernard, B., Mueller, C., Kitt, M., Driscoll, R., \& Tak, S. (2008). Mental health outcomes in police personnel after Hurricane Katrina. Journal of Occupational and Environmental Medicine, 50, 689-695. https://doi.org/10.1097/JOM.0b013e3181638685.

World Health Organization. (n.d.). Coronavirus [WWW Document]. https://www.who. int/emergencies/diseases/novel-coronavirus-2019. Accessed 4.15.20.

Zhang, J., Wu, W., Zhao, X., \& Zhang, W. (2020). Recommended psychological crisis intervention response to the 2019 novel coronavirus pneumonia outbreak in China: A model of West China Hospital. Precision Clinical Medicine., 3, 3-8. https://doi.org/10.1093/pcmedi/pbaa006.

Publisher's Note Springer Nature remains neutral with regard to jurisdictional claims in published maps and institutional affiliations. 